\title{
Origin of [OI] 5577 in the Airglow and the Aurora
}

\author{
Franklin E. Roach, James W. McCaulley, and Edward Marovich \\ (January 30, 1959)
}

The distribution of 5577 zenith intensities at stations in the subauroral zone is found to be unimodal with no discontinuity at the visual threshold. This is interpreted as evidence that 5577 airglow and 5577 aurora may have a common origin.

\section{Introduction}

It is customary to refer to [OI] 5577 as airglow if it is invisible and as aurora if it is visible. Thus, the physiological visual threshold (at approximately 1,000 rayleighs ${ }^{1}$ for extended objects) has been assumed to have a physical significance in the upper atmosphere with different mechanisms operative above and below the threshold. The purpose of this paper is to inquire into the existence of a physical criterion to distinguish between 5577 airglow and 5577 aurora. $^{2}$

\section{Analysis of St. Amand and Ashburn}

One approach to the problem has been offered by St. Amand and Ashburn. ${ }^{3}$ They suggest that a study of the statistical distribution of absolute 5577 intensities at a given location may yield information as to a common or separate origin for airglow and aurora. If there is a common origin, it might be expected that the distribution of intensities would be unimodal with a continuous gradation from the invisible (airglow) to the visible (aurora). If, on the other hand, the origins are separate and distinct, one would expect a discontinuity ${ }^{4}$ of some kind in the distribution curve, the most likely being a bimodal distribution. ${ }^{5}$ In figure 1 , schematic representations of the two possibilities are shown. The two sketches on the left indicate a schematic bimodal distribution. In the subauroral zone, auroras are infrequent and this is indicated by the relatively smaller area under the aurora curve than under the airglow curve. In the auroral zone, the relative areas are shown reversed. Actually, the wings of the two distribution curves may overlap, but the essence of the argument is that there should be a discontinuity in the composite distribution if the two phenomena are independent in nature and origin. In the right-hand part of figure 1 , schematic distributions are shown for the single-

\footnotetext{
1. For a discussion of the "rayleigh" unit of intensity see D. M. Hunten, F. E. Roach, and J. W. Chamberlain, A photometric unit for the airglow and the aurora, J. Atmospheric and Terrest. Phys. 8, 345 (1956). If the surface brightness (B) is measured in $10^{6}$ quanta $/ \mathrm{cm}^{2} \cdot \mathrm{sec} \cdot$ steradian, then the intensity in ray-

leighs $(\mathrm{R})$ is $4 \pi \mathrm{B}$. For bright auroras it is convenient to use the kilorayleigh
$(\mathrm{kR})$ as a unit.
2 Throughout this paper the discussion is strietly limited to the single emission 2 Throughout this paper the discussion is strictly limited
5577 and should not be generalized to any other radiation.

3 P.St. Amand and E. V. A shburn, The frequency distribution of the intensity of aurorae and the night airglow for 5577 [OI], J. Geophys. Research 60, 112 (1955). "In this paper the word "discontinuity" is used with the general implication of a "break" rather than in the strict mathematical sense.

5 It should be mentioned that bimodality almost certainly indicates heterogeneity, but there may be heterogeneity without bimodality.
}

origin hypothesis, their critical characteristic being the lack of any discontinuity.

In figure 2, a replot of the histogram of St. Amand and Ashburn is shown with a regrouping of the data to correspond to class intervals of $50 \mathrm{R}$ rather than the $10 \mathrm{R}$ that they used. They put an approximately normal curve through the plot on the basis of which they were able to state that an intensity corresponding to a just visible aurora should occur only "once or twice in geologic time." Because auroras do occur occasionally, though rarely, in southern California, the implication is that an aurora is a completely separate phenomenon from the airglow (5577).

Two comments are in order on the analysis by St. Amand and Ashburn: (1) Since they used mean nightly values of 5577 intensity, their prediction must refer to cases in which the mean nightly intensity will be of auroral intensity, which is, of course, much less probable than that an aurora will occur for a short time during a night; (2) the assumption of a normal curve is a critical feature of their analysis. Even a slight positive skewness in the distribution would change the prediction radically. As is shown in the next section, positive skewness is a general characteristic of all the distributions for which a substantial amount of data is available.

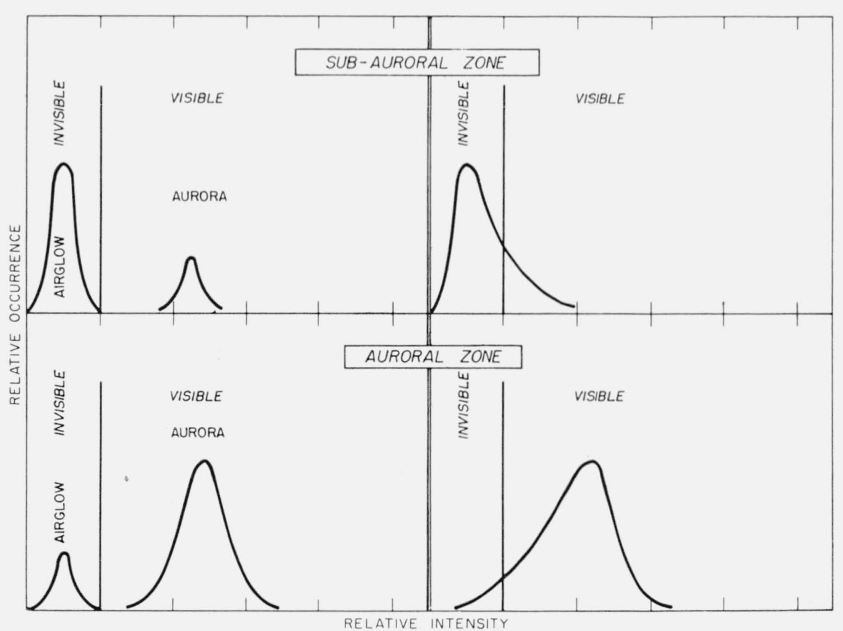

FIGURE 1. Schematic representation of the common origin hypothesis (right) and the separate origin hypothesis (left) for the $55 \% 7$ airglow and the 55\% 7 aurora. 
In their note on the problem, St. Amand and Ashburn examined the distribution of the nightly mean intensities for 86 nights at Cactus Peak, Calif., calling attention to the need for a larger statistical sample in order to give a more definitive solution. During the International Geophysical Year, a much larger sample is available for analysis. In the present study, some of this accumulated information is used to reexamine the problem.

\section{Analysis of the IGY Data}

At the present time, there are in the files of the Boulder World Data Center hourly zenith airglow intensities from 15 stations for approximately the first half of the International Geophysical Year. The distributions of 5577 zenith intensities without a single exception have a pronounced positive skewness so that, although the higher intensities near and exceeding the visual threshold are rare, they do not drop to zero occurrence. Furthermore, the distributions are in all cases smooth with no indication of any discontinuity. The strength of the above empirical fact can be appreciated when it is recalled that the calibrations and instrumentation are quite independent at the several stations.

The first treatment of the data from any given station should be the privilege of those in charge of the station so the details are not given here for airglow observing stations not under supervision of the authors. Since the distributions at Fritz Peak, Colo., and at Rapid City, S. Dak., are typical of those obtained at the other locations, the results are illustrated for these two stations plus the composite results for all the 15 IGY stations without individual identification.
In table 1 are shown the percentage occurrence by class interval and the cumulative percentage occurrence for: (a) Cactus Peak for the mean nightly intensities according to St. Amand and Ashburn (see section 2); (b) Fritz Peak hourly zenith intensities from July 1957 to September 1958; (c) Rapid City hourly zenith intensities from September 1957 to July 1958; and (d) the composite results for 7515 individual zenith intensities from 15 IGY stations.

In figure 3 , the distributions for Rapid City, Fritz Peak, and the composite for all IGY stations are shown. In all three cases, the departure from a symmetrical normal distribution is clear. The large sample (7515) for the composite IGY results gives an unusually smooth distribution with the positive skewness clearly evident.

\section{Discussion}

To summarize the results obtained, it is noted: (a) For the stations studied there is evidence for a unimodal distribution of intensities with no apparent discontinuities; (b) the distribution shows a positive skewness so that there is a definite smooth occurrence of intensities from the more probable airglow values near 200 to $300 \mathrm{R}$ to and past the visual threshold near $1,000 \mathrm{R}$.

Referring now to the introductory remarks, the facts are noted to be consistent with the hypothesis that 5577 airglow and aurora have a common nature and origin, at least for the stations in the subauroral zone. A further numerical test of the hypothesis is whether the distributions predict the occurrence of visual auroras. According to E. H. Vestine ${ }^{6}$ there

${ }^{6}$ E. H. Vestine, The geographic incidence of aurora and magnetic disturbance northern hemisphere, Terrestrial Magnetism and Atmospheric Elec. 49, 77 (1944),

TABLE 1. Intensity frequency distributions

\begin{tabular}{|c|c|c|c|c|c|c|c|c|}
\hline \multirow{4}{*}{ Range } & \multicolumn{2}{|c|}{$\begin{array}{c}\text { Cactus Peak } \\
\text { (nightly means) }\end{array}$} & \multicolumn{2}{|c|}{$\begin{array}{c}\text { Fritz Peak } \\
\text { (hourly values) }\end{array}$} & \multicolumn{2}{|c|}{$\begin{array}{c}\text { Rapid City } \\
\text { (hourly values) }\end{array}$} & \multicolumn{2}{|c|}{$\begin{array}{c}\text { IGY } \\
\text { (hourly values) }\end{array}$} \\
\hline & \multicolumn{8}{|c|}{ Size of sample } \\
\hline & \multicolumn{2}{|c|}{86} & \multicolumn{2}{|c|}{832} & \multicolumn{2}{|c|}{593} & \multicolumn{2}{|c|}{7515} \\
\hline & Class & Cumulative & Class & Cumulative & Class & Cumulative & Class & Cumulative \\
\hline$R$ & $\%$ & $\%$ & $\%$ & $\%$ & $\%$ & $\%$ & $\%$ & $\%$ \\
\hline 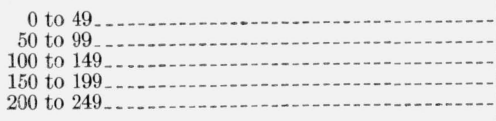 & $\begin{array}{r}0.0 \\
2.3 \\
8.1 \\
18.6 \\
23.3\end{array}$ & $\begin{array}{r}0.0 \\
2.3 \\
10.5 \\
29.1 \\
52.3\end{array}$ & $\begin{array}{r}0.1 \\
.2 \\
1.3 \\
7.0 \\
10.7\end{array}$ & $\begin{array}{r}0.1 \\
.3 \\
1.6 \\
8.6 \\
19.3\end{array}$ & $\begin{array}{r}0.2 \\
3.2 \\
10.8 \\
15.7 \\
19.1\end{array}$ & $\begin{array}{r}0.2 \\
3.4 \\
14.2 \\
29.8 \\
49.9\end{array}$ & $\begin{array}{r}0.1 \\
2.8 \\
7.5 \\
11.1 \\
12.8\end{array}$ & $\begin{array}{r}0.1 \\
3.0 \\
10.4 \\
21.6 \\
31.4\end{array}$ \\
\hline $\begin{array}{l}250 \text { to } 299 \\
300 \text { to } 349 \\
450 \text { to } 399 \\
450 \text { to } 44999\end{array}$ & $\begin{array}{r}16.3 \\
16.3 \\
9.3 \\
2.3 \\
2.3\end{array}$ & $\begin{array}{l}68.6 \\
84.9 \\
94.2 \\
96.5 \\
98.8\end{array}$ & $\begin{array}{r}11.7 \\
12.9 \\
11.3 \\
10.1 \\
8.7\end{array}$ & $\begin{array}{l}31.0 \\
43.9 \\
55.2 \\
65.3 \\
74.0\end{array}$ & $\begin{array}{r}14.2 \\
11.3 \\
7.8 \\
6.2 \\
3.0\end{array}$ & $\begin{array}{l}63.1 \\
74.4 \\
82.1 \\
88.4 \\
91.4\end{array}$ & $\begin{array}{r}13.3 \\
12.5 \\
9.8 \\
7.3 \\
6.2\end{array}$ & $\begin{array}{l}\text { 47. } 7 \\
60.2 \\
70.0 \\
77.2 \\
83.4\end{array}$ \\
\hline $\begin{array}{l}500 \text { to } 549 \\
650 \text { to } 599 \text { to } 649 \\
650 \text { to } 699 \\
700 \text { to } 749\end{array}$ & 1. 2 & 100.0 & $\begin{array}{l}6.6 \\
4.6 \\
4.4 \\
2.4 \\
1.9\end{array}$ & $\begin{array}{l}80.6 \\
85.2 \\
89.6 \\
92.0 \\
93.9\end{array}$ & \begin{tabular}{l|}
3.2 \\
0.5 \\
1.2 \\
0.8 \\
.7
\end{tabular} & $\begin{array}{l}94.6 \\
95.1 \\
96.3 \\
97.1 \\
97.8\end{array}$ & $\begin{array}{l}4.9 \\
3.4 \\
2.3 \\
1.8 \\
1.4\end{array}$ & $\begin{array}{l}88.3 \\
91.7 \\
94.0 \\
95.8 \\
97.2\end{array}$ \\
\hline $\begin{array}{l}750 \text { to } 799 \\
800 \text { to } 849 \\
900 \text { to } 899 \\
950 \text { to } 9499\end{array}$ & & & $\begin{array}{r}1.2 \\
0.8 \\
.8 \\
.5 \\
.4\end{array}$ & $\begin{array}{l}95.1 \\
95.9 \\
96.7 \\
97.2 \\
97.6\end{array}$ & $\begin{array}{l}.0 \\
.7 \\
.0 \\
.3 \\
.0\end{array}$ & $\begin{array}{l}97.8 \\
98.5 \\
98.5 \\
98.8 \\
98.8\end{array}$ & $\begin{array}{r}0.8 \\
.6 \\
.4 \\
.3 \\
.2\end{array}$ & $\begin{array}{l}97.9 \\
98.5 \\
98.9 \\
99.2 \\
99.4\end{array}$ \\
\hline
\end{tabular}


is a 4.6 percent occurrence of auroras at Rapid City $\left(\Phi=53^{\circ} \mathrm{N}\right)$ and 2.4 percent for Fritz Peak $\left(\Phi=49^{\circ} \mathrm{N}\right)$.

It is not possible to make a definitive comparison between the predictions of Vestine and the present observations because the present intensities refer to the zenith and the curve of Vestine predicts an aurora in any part of the sky. However, it is probably significant that the cumulative frequencies leave a residual (see table 1 ) of 1.2 percent for Rapid City and 2.4 percent for Fritz Peak for intensities greater than 1,000 R, which are similar to the quantities from Vestine's curve. During the period covered, there were visible auroras at both stations, the observations of which are included in the general statistical results. That the residual percentage over $1,000 \mathrm{R}$ for Fritz Peak is greater than that for Rapid City is surprising, but it is suggested that this may be due to the smallness of the samples. However, the maximum zenith intensities for Rapid City $(5,870 \mathrm{R})$ and for Fritz Peak $(2,830 \mathrm{R})$ reflect the greater intensity of individual auroras at Rapid City, as is to be expected because it is closer to the auroral zone.

\section{Conclusion}

Evidence has been presented consistent with the hypothesis that 5577 airglow and 5577 aurora are of a common origin. It is of critical importance as

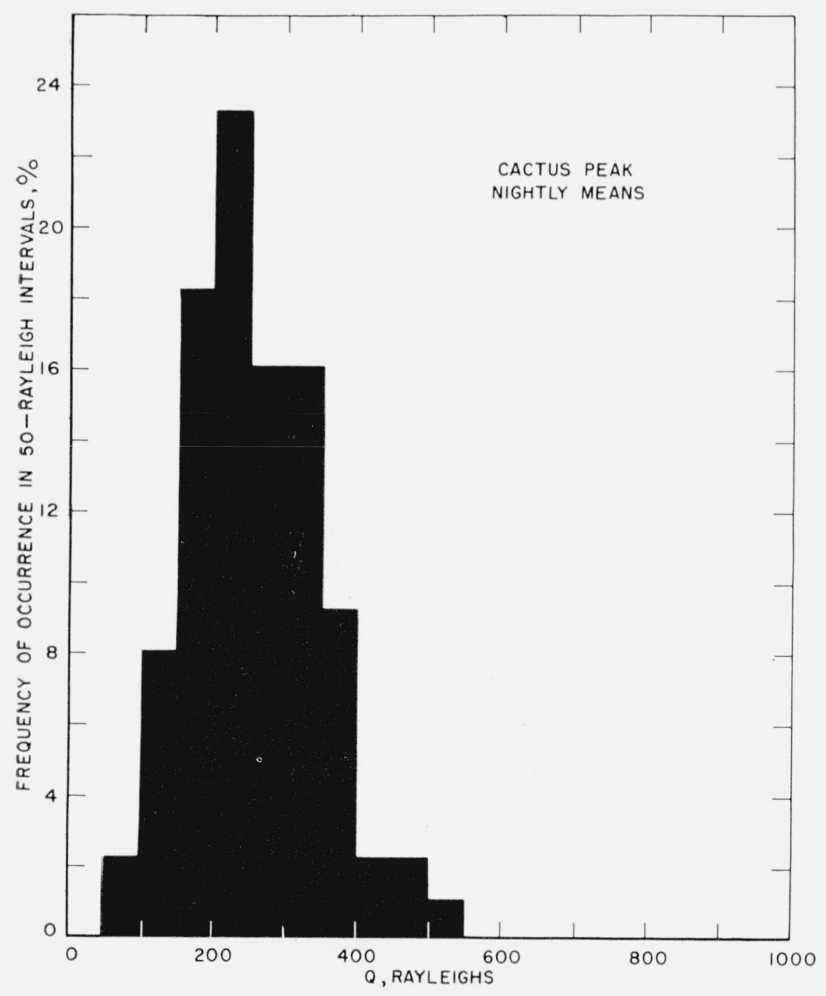

FIgURE 2. Distribution of $55 \% \mathrm{y}$ zenith intensities at Cactus Peak, Calif., for nightly means.

(From data of St. Amand and Ashburn, see footnote 3.). a further test of the hypothesis that similar analyses be carried out at stations closer to the auroral zone where visual auroras are more frequent. In the following paper, some results are shown from Thule, Greenland, near the center of the auroral zone.

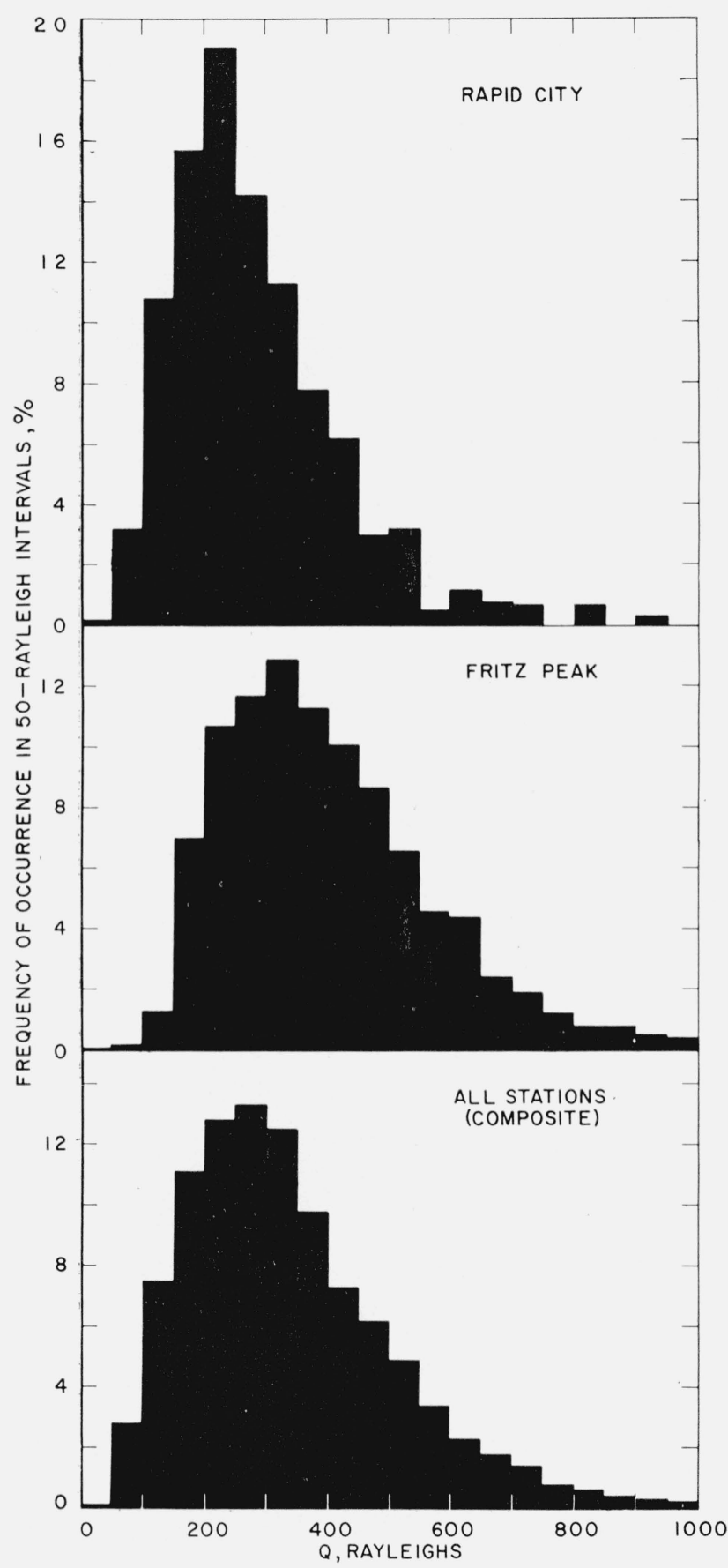

Figure 3. Distribution of $55 \%$ zenith intensities at Rapid City, S. Dak., and Fritz Peak, Colo, and for the composite of $15 I G Y$ stations in the subauroral zone. 
The principal thesis of this paper is that there is no apparent discontinuity in 5577 distributions near the human visual threshold and that, therefore, this threshold should not be used to distinguish between two physical phenomena such as the airglow and the aurora. One often hears the statement from persons living close to the auroral zone that "there is some kind of an aurora every clear night" which can be paralleled by a similar statement by inhabitants of the subauroral zone that "there is 5577 airglow every clear night". Could it be that these statements correspond to physically similar situa- tions at different average intensity levels? There remains the possibility of a break in the distribution somewhere in the four decades of 5577 intensity between a weak airglow $(100 \mathrm{R})$ and an aurora IV $(1,000 \mathrm{kR})$ but it does not show up at the visual threshold $(1,000 \mathrm{R})$ in the subauroral zone. This paper is, therefore, a challenge to auroral observers to search for some quantitative factor in the aurora itself that can be used as a true discriminent.

Boulder, Colo. (Paper 63D1-2). 